\title{
Red Cell Distribution Width and Mean Platelet Volume in Patients With Pityriasis Rosea
}

\author{
Gunseli Sefika Pancar ${ }^{\mathrm{a}, \mathrm{c}}$, Oznur Eyupoglu ${ }^{\mathrm{b}}$
}

\begin{abstract}
Background: Pityriasis rosea (PR) is an inflammatory skin disorder of unknown etiology. However, it is suggested to be related with the reactivation of human herpes virus 7 (HHV-7) and/or HHV-6. It is sometimes diffucult to distinguish PR from PR-like drug eruptions and other inflammatory disorders, so we need new parameters which are cheap and easy in determining PR. Red blood cell distribution width (RDW) and mean platelet volume (MPV) have been studied as inflammatory markers in recent studies. However, the RDW and MPV in PR patients have not been investigated. This is the first study investigating RDW and MPV parameters in PR.
\end{abstract}

Methods: This was a retrospective study of 127 patients and 127 healthy controls. MPV, RDW and the other laboratory tests were recorded.

Results: RDW levels of patients with PR were significantly lower than those of the controls $(13.66 \pm 2.68$ and $14.00 \pm 1.39, \mathrm{P}<0.01)$. The other inflammatory markers such as MPV $(9.97 \pm 0.99$ and 10.0 $\pm 1.06, \mathrm{P}=0.7)$ and platelet $(2.66 .29 \pm 62.85$ and $277.41 \pm 63.50, \mathrm{P}$ $=0.3$ ) were studied and statistically significant differences were not obtained. There were no significant differences found between the patient group and healthy controls in terms of hemoglobin, hematocrite, C-reactive protein (CRP), sedimentation, mean corpuscular volume (MCV), aspartate aminotransferase (AST), red blood cell (RBC), alanine aminotransferase (ALT), blood urea nitrogen (BUN), and creatinine parameters $(\mathrm{P}>0.05)$.

Conclusion: RDW can be used as a marker in diagnosing PR.

Keywords: Red blood cell distrubution width; Mean platelet volume; Pityriasis rosea; Laboratory parameters

Manuscript accepted for publication March 22, 2016

aDepartment of Dermatology, Samsun State Hospital, Samsun, Turkey

${ }^{b}$ Department of Statistics, Ondokuz Mayis University School of Medicine Samsun, Turkey

${ }^{\mathrm{c} C}$ Corresponding Author: Gunseli Sefika Pancar, Department of Dermatology, Samsun State Hospital, TR-55000, Samsun, Turkey.

Email: drgunselisefika@hotmail.com

doi: http://dx.doi.org/10.14740/jocmr2535w

\section{Introduction}

Pityriasis rosea (PR) is an acute, self-limiting exanthematous disease which is usually diagnosed in healthy adolescents and young adults. It is characterized by oval erythematous-squamous lesions of the trunk and limbs that usually spare face, scalp, palms and soles [1]. The cause of PR remains elusive; however, constitutional symptoms, clinical features, and epidemiologic data all go through the virologic investigation and it is proposed to be associated with the endogenous reactivation of human herpes virus 6 (HHV-6) and/or HHV-7 infection in conditions of altered immunity [2-4]. Besides, many drugs have been suggested as possible triggers of PR-like eruptions and there are lots of skin disorders that can be difficult to distinguish from PR. Also, sometimes histopathological features can not help in differentiating PR from others. Therefore, finding a marker which indicates PR in laboratory tests is important.

Red blood cell distribution width (RDW) is a parameter which is routinely reported in complete blood count (CBC) analysis and expressing variation in size of the red blood cells (RBCs). It is calculated by dividing the standard deviation of $\mathrm{RBC}$ volume by mean corpuscular volume (MCV) and used to find causes of anemia [5]. Besides RDW, mean platelet volume (MPV) is also a determinant of inflammation which is a measure of platelet size. They can be easily measured by automated hematology analyzer in routine complete blood cell analysis [6].

Recently, RDW and MPV have been studied in various diseases. RDW was considered an inflammatory marker for heart failure, rheumatoid arthritis, inflammatory bowel disease and psoriasis [7-9]. MPV has been studied as an inflammatory marker of cutaneous vasculitis, psoriasis, cardiovascular disease and rheumatologic diseases $[10,11]$. Since there is not a study in the liteature regarding the relationship between RDW, MPV and PR, the purpose of this study was to investigate the RDW and MPV levels in PR patients compared with healthy controls.

\section{Methods}

This was a retrospective study of patients who had been diagnosed with PR by histopathological examination between 
Table 1. Summary of Laboratory Parameters

\begin{tabular}{llll}
\hline Parameters & Pityriasis rosea & Control group & P value \\
\hline Age $($ years $)$ & $28.91 \pm 14.72$ & $30 \pm 10.49$ & 0.02 \\
White blood cell $\left(10^{3} / \mu \mathrm{L}\right)$ & $8.11 \pm 6.09$ & $7.80 \pm 1.79$ & 0.5 \\
Neutrophil $\left(10^{3} / \mu \mathrm{L}\right)$ & $4.42 \pm 1.92$ & $4.75 \pm 1.43$ & 0.3 \\
Lymphocyte $\left(10^{3} / \mu \mathrm{L}\right)$ & $33.54 \pm 8.81$ & $30.93 \pm 7.30$ & 0.3 \\
Red blood cell $\left(10^{6} / \mu \mathrm{L}\right)$ & $4.86 \pm 0.41$ & $4.71 \pm 0.44$ & 0.2 \\
Hematocrite & $42.60 \pm 3.92$ & $40.75 \pm 4.00$ & 0.6 \\
Hemoglobin $(\mathrm{g} / \mathrm{dL})$ & $13.99 \pm 1.45$ & $13.11 \pm 1.47$ & 0.2 \\
Mean corpuscular volume (fL) & $87.60 \pm 4.86$ & $86.70 \pm 6.85$ & 0.5 \\
Mean corpuscular hemoglobin $(\mathrm{fL})$ & $28.76 \pm 1.95$ & $27.90 \pm 2.63$ & 0.2 \\
Mean platelet volume (fL) & $9.97 \pm 0.99$ & $10.00 \pm 1.06$ & 0.7 \\
Platelet $\left(10^{3} / \mu \mathrm{L}\right)$ & $266.29 \pm 62.85$ & $277 \pm 63.5$ & 0.3 \\
Red cell distribution width $(\%)$ & $13.66 \pm 2.68$ & $14.00 \pm 1.39$ & $<0.01$ \\
Urea nitrogen $(\mathrm{mg} / \mathrm{dL})$ & $26.67 \pm 7.88$ & $24.06 \pm 8.68$ & 0.3 \\
Creatinine $(\mathrm{mg} / \mathrm{dL})$ & $0.72 \pm 0.175$ & $0.81 \pm 1.5$ & 0.7 \\
Aspartate aminotransferase $(\mathrm{IU} / \mathrm{L})$ & $19.50 \pm 7.00$ & $17.53 \pm 5.4$ & 0.3 \\
Alanine aminotransferase & $20.19 \pm 15.96$ & $17.00 \pm 18.02$ & 0.1 \\
Sedimentation $(\mathrm{IU} / \mathrm{L})$ & $15.46 \pm 15.65$ & $17.47 \pm 19.03$ & 0.2 \\
C-reactive protein $(\mathrm{mg} / \mathrm{dL})$ & $2.13 \pm 7.6$ & $2.35 \pm 7.8$ & 0.4 \\
\hline
\end{tabular}

Data are presented as mean \pm standard deviation.

2013 and 2015 at Samsun Gazi State Hospital in Samsun, Turkey. Demographic characteristics and laboratory information were retrieved from the database of the center. Control group was selected from healthy subjects who were admitted in our hospital for rutine controls. Data collected included age, sex and laboratory information.

Patients who had infection, malnutrition, anemia, immunodeficiency, chronic disease, chronic inflammatory skin disease, rheumatologic disease, hematologic disease, and cardiac disease, and who used medication were excluded from the study.

Laboratory parameters included RDW, MPV, hemoglobin $(\mathrm{Hb}, \mathrm{g} / \mathrm{dL})$, hematocrit, neutrophil and lymphocyte counts, RBC count, MCV (fL), white blood cell (WBC) count and platelet (Plt) count. In addition to above items, blood urea nitrogen (BUN), creatinine (Crea), aspartate aminotransferase (AST), alanine aminotransterase (ALT), sedimentation and Creactive protein (CRP) were recorded.

\section{Statistical analysis}

Statistical analysis was completed using SPSS 17.0 for Windows (Chicago, IL, USA). Continous parameters are described as mean \pm standard deviation and qualitative parameters as number (10\%). Comparisons between PR patients and control subjects were performed with Student's $t$-test and Fisher's exact test. Statistical significance was set at $\mathrm{P}<0.05$. Chi-square test was used to compare categorical variables between independent groups.

\section{Results}

One hundred and twenty-seven PR patients and 127 healthy controls were included in this study.

There was no statistically significant difference between groups according to sex and age $(\mathrm{P}=0.4)$.

$\mathrm{Hb}$, hematocrit, $\mathrm{WBC}$, and $\mathrm{RBC}$ levels did not show any significant difference. RDW level was $13.66 \pm 2.68$ in PR group and $14.00 \pm 1.39$ in control group and the RDW level was statistically lower in PR group $(\mathrm{P}<0.004)$. The other inflammatory markers such as MPV $(9.97 \pm 0.99$ and $10.0 \pm$ $1.06, \mathrm{P}=0.7)$ and Plt (2.66.29 \pm 62.85 and 277.41 $\pm 63.50, \mathrm{P}$ $=0.3$ ) were also evaluated and statistically significant differences were not obtained $(\mathrm{P}=0.3)$.

Neutrophil count was $4.42 \pm 1.92$ in PR group and $4.75 \pm$ 1.43 in control group. Lymphocyte count is $33.54 \pm 8.81$ in PR group and $30.93 \pm 7.30$ in control group. Statistical analysis of neutrophil and lymphocyte counts did not show any difference among groups $(\mathrm{P}=0.3)$.

There were no significant differences between the patient group and healthy controls in terms of MCV, mean corpuscular hemoglobin, CRP, sedimentation, AST, ALT, BUN, and Crea parameters $(\mathrm{P}>0.05)$.

The laboratory findings are summarized in Table 1.

\section{Discussion}

According to this study, RDW level is significantly lower 
in patients with PR compared with healthy controls. To our knowledge, this is the first study indicating that RDW value is decreased in PR patients.

PR is a self-limited inflammatory skin eruption. The first clinical presentation is a scaly erythematous plaque named "herald" patch than fallowing secondary skin eruption distributed along the skin tension line in most of cases. The immunohistochemical studies revealed that it is a cell-mediated immunoreaction composed of predominantly $\mathrm{CD}^{+} \mathrm{T}$ lymphocytes and $\mathrm{CD}^{+} 8^{+}$histiocytes [12]. Viral agents, autoimmunity, psychogenic status and numerous drugs have been proposed as triggered factors of PR [13]. Many atypical forms have been reported in the literature. Vesicular PR, unilateral PR, purpuric PR, papular and erythema multiforme-like PR and localized PR have been mentioned in recent studies [14-18].

Clinical features and prodromal symptoms (malaise, sore throat, fever, and flu-like symptoms) suggest an infectious etiology. Bacterial, viral and fungal infections were postulated as triggered reasons of PR and recent studies focused on HHV-6 and 7 viral infections [19]. Canpolat et al evaluated the HHV6, HHV-7, Epstein-Barr virus (EBV) and cytomegalovirus (CMV) infections in PR by polymerase chain reaction, indirect immunofluorescence and immunosorbent assay test and only HHV-6 and HHV-7 were indicated as possible factors of PR according to their study [20].

Broccolo et al also elucidated the HHV-6, HHV-7 and their DNA load in plasma, peripheral blood and mononuclear cells in PR. PCR assays of tissues were performed. HHV-6 and $\mathrm{HHV}-7$ antigens and their DNA were detected in plasmas and HHV-7 viremia was thought to be associated with the PR [21].

The RDW and MPV have been identified as markers of inflammation. They predict the prognosis across several types of diseases. Cardiovascular disorders, inflammatory bowel diseases, psoriasis, rheumatoid arthritis, Behcet's disease, brucellosis and vasculitis are the most known diseases related with these parameters. However, the value of RDW and MPV in PR has not been studied. We evaluated this association in this study.

RDW reflects the variation in size of the RBCs. It is an automated measure of RBC size heterogeneity (e.g., anisocytosis). Proinflammatory cytokines are thought to be responsible for inducing changes in erythroid progenitor cells, erythropoietin and RBCs in inflammatory disorders. Interleukin 1 (IL-1), IL-6, IL-10 and TNF-alpha are the main cytokines and systemic increases of these inflammatory markers are suggested to be the reason of elevated RDW levels [7, 22, 23]. However, the exact reason of the elevated RDW levels is unknown.

Topal et al revealed that MPV value was higher in atopic eczema of preschool children and RDW value was not statistically different [24]. Farkas et al evaluated the RDW levels in systemic sclerosis and it was found to be valuable measure of multiple pathological processes including extensive vasculopathy, fibrosis or ongoing inflammation. In cardiovascular studies, it has revealed that RDW may indicate an impairment of cardiorespiratory function [25]. Kim et al studied the RDW in psoriasis and suggested that RDW is increased in patients with psoriasis and can reflect the inflammatory status of patients [9].

Lou et al studied RDW values in hepatitis B virus (HBV)- infected patients. RDW was found to be associated with mortality in HBV-infected patients [26]. Also, Karagoz et al investigated MPV and RDW values which were significantly higher and associated with severity in HBV-infected patients.

According to above studies, we can say RDW is largely overlooked in chronic systemic diseases and chronic inflammatory dermatologic diseases. However, its role in temporary viral infections and acute dermatological diseases has not been well defined. From the point of this view, we decided to evaluate the RDW and MPV levels of an acute inflammatory skin disorder which was suggested to be triggered by a viral infection. According to this study, RDW level was statistically lower $(\mathrm{P}<0.01)$ when compared with control group. The variations in RDW may be associated with anemia. We evaluated anemia parameters such as $\mathrm{Hb}$, hematocrite, $\mathrm{RBC}, \mathrm{MCV}$ and Plt count to exclude this suggestion and they were not statistically different between PR and control groups. In addition to these, neutrophil count, lymphocyte count, liver and urine functional tests and sedimentation were in normal range.

Emans et al investigated the relationship between RDW and erythropoietic activity. They suggested that RDW was negatively correlated with functional iron availability (reticulocyte $\mathrm{Hb}$ content and transferrin saturation) and positively correlated with erythropoietic activity (immature reticulocyte fraction) [27]. We suggested that during this acute disease, the causative viral infection could suppress the bone narrow and this causes a temporary loss in erythropoietic activity and could be the reason of the reduction in RDW levels. However, cytogenetic and bone narrow evaluation were not done in this study. Also, the other inflammatory marker (MPV) did not show statistically significant difference. Prospective studies with a large number of patients are needed to be done to confirm the prognostic value of RDW and MPV in PR. We could not evaluate ferritin level and this was the limitation of our study. Beside this, there are a lot of studies related with drugs and their side effects confirming as PR-like eruptions in literature. Examples are terbinafine, bupropion, infliximab, rituximab, etc. We exactly do not know how to distinguish them from PR itself, so RDW could be a new approch while evaluating PR and PR-like eruptions. In the light of this study, future studies can focus on the difference of RDW and MPV levels between PR and drug-induced PR-like eruptions.

\section{References}

1. Drago F, Broccolo F, Rebora A. Pityriasis rosea: an update with a critical appraisal of its possible herpesviral etiology. J Am Acad Dermatol. 2009;61(2):303-318.

2. Watanabe T, Kawamura T, Jacob SE, Aquilino EA, Orenstein JM, Black JB, Blauvelt A. Pityriasis rosea is associated with systemic active infection with both human herpesvirus-7 and human herpesvirus-6. J Invest Dermatol. 2002;119(4):793-797.

3. Drago F, Javor S, Bruzzone L, Parodi A, Picciotto A. Pityriasis rosea in a hepatitis B-positive patient treated with pegylated interferon alpha2a: report of a case and review of the literature. Dermatology. 2014;228(1):10-13.

4. Drago F, Broccolo F, Ciccarese G, Rebora A, Parodi A. 
Persistent pityriasis rosea: an unusual form of pityriasis rosea with persistent active HHV-6 and HHV-7 infection. Dermatology. 2015;230(1):23-26.

5. Hoffmann JJ, Nabbe KC, van den Broek NM. Effect of age and gender on reference intervals of red blood cell distribution width (RDW) and mean red cell volume (MCV). Clin Chem Lab Med. 2015;53(12):2015-2019.

6. Schoorl M, van Pelt J, Bartels PC. Application of Innovative Hemocytometric Parameters and Algorithms for Improvement of Microcytic Anemia Discrimination. Hematol Rep. 2015;7(2):5843.

7. Lippi G, Targher G, Montagnana M, Salvagno GL, Zoppini G, Guidi GC. Relation between red blood cell distribution width and inflammatory biomarkers in a large cohort of unselected outpatients. Arch Pathol Lab Med. 2009;133(4):628-632.

8. Song CS, Park DI, Yoon MY, Seok HS, Park JH, Kim HJ, Cho YK, et al. Association between red cell distribution width and disease activity in patients with inflammatory bowel disease. Dig Dis Sci. 2012;57(4):1033-1038.

9. Kim DS, Shin D, Jee H, Kim TG, Kim SH, Kim do Y, Kim SM, et al. Red blood cell distribution width is increased in patients with psoriasis vulgaris: A retrospective study on 261 patients. J Dermatol. 2015;42(6):567-571.

10. Kim DS, Shin D, Kim TG, Kim SH, Kim do Y, Kim SM, Lee MG. Red blood cell distribution width as a useful indicator to predict systemic vasculitis in patients with cutaneous vasculitis. Rheumatol Int. 2015;35(4):719-725.

11. Gasparyan AY, Ayvazyan L, Mikhailidis DP, Kitas GD. Mean platelet volume: a link between thrombosis and inflammation? Curr Pharm Des. 2011;17(1):47-58.

12. Hussein MR, Abdel-Magid WM, Saleh R, Nada E. Phenotypical characteristics of the immune cells in allergic contact dermatitis, atopic dermatitis and pityriasis rosea. Pathol Oncol Res. 2009;15(1):73-79.

13. Polat M, Uzun O, Ors I, Boran C. Pityriasis rosea-like drug eruption due to bupropion: a case report. Hum Exp Toxicol. 2014;33(12):1294-1296.

14. Balci DD, Hakverdi S. Vesicular pityriasis rosea: an atypical presentation. Dermatol Online J. 2008;14(3):6.

15. Ataseven A, Kurtipek GS, Akyurek FT, Kucukosmanoglu I, Dilek N. Unilateral pityriasis rosea. Indian Dermatol Online J. 2014;5(4):528-529.
16. Chuh A, Zawar V, Lee A. Atypical presentations of pityriasis rosea: case presentations. J Eur Acad Dermatol Venereol. 2005;19(1):120-126.

17. Sinha S, Sardana K, Garg VK. Coexistence of two atypical variants of pityriasis rosea: a case report and review of literature. Pediatr Dermatol. 2012;29(4):538-540.

18. Ahmed I, Charles-Holmes R. Localized pityriasis rosea. Clin Exp Dermatol. 2000;25(8):624-626.

19. Guarneri F, Cannavo SP, Minciullo PL, Gangemi S. Pityriasis rosea of Gibert: immunological aspects. J Eur Acad Dermatol Venereol. 2015;29(1):21-25.

20. Canpolat Kirac B, Adisen E, Bozdayi G, Yucel A, Fidan I, Aksakal N, Gurer MA. The role of human herpesvirus 6, human herpesvirus 7, Epstein-Barr virus and cytomegalovirus in the aetiology of pityriasis rosea. J Eur Acad Dermatol Venereol. 2009;23(1):16-21.

21. Broccolo F, Drago F, Careddu AM, Foglieni C, Turbino L, Cocuzza CE, Gelmetti C, et al. Additional evidence that pityriasis rosea is associated with reactivation of human herpesvirus-6 and -7. J Invest Dermatol. 2005;124(6):1234-1240.

22. Weiss G, Goodnough LT. Anemia of chronic disease. N Engl J Med. 2005;352(10):1011-1023.

23. Leader A, Pereg D, Lishner M. Are platelet volume indices of clinical use? A multidisciplinary review. Ann Med. 2012;44(8):805-816.

24. Topal E, Celiksoy MH, Catal F, Karakoc HT, Karadag A, Sancak R. The Platelet Parameters as Inflammatory Markers in Preschool Children with Atopic Eczema. Clin Lab. 2015;61(5-6):493-496.

25. Farkas N, Szabo A, Lorand V, Sarlos DP, Minier T, Prohaszka Z, Czirjak L, et al. Clinical usefulness of measuring red blood cell distribution width in patients with systemic sclerosis. Rheumatology (Oxford). 2014;53(8):14391445.

26. Lou Y, Wang M, Mao W. Clinical usefulness of measuring red blood cell distribution width in patients with hepatitis B. PLoS One. 2012;7(5):e37644.

27. Emans ME, van der Putten K, van Rooijen KL, Kraaijenhagen RJ, Swinkels D, van Solinge WW, Cramer MJ, et al. Determinants of red cell distribution width (RDW) in cardiorenal patients: RDW is not related to erythropoietin resistance. J Card Fail. 2011;17(8):626-633. 